\title{
Ligand Binding Properties of the N-Terminal Domain of Riboflavin Synthase from Escherichia coli
}

\author{
Chan Yong Lee ${ }^{1, *}$, Boris Illarionov ${ }^{2}$, Young-Eun Woo ${ }^{1, \#}$, Kristina Kemter ${ }^{2}$, Ryu-Ryun Kim ${ }^{1}$, Sabine Eberhardt ${ }^{2}$, \\ Mark Cushman ${ }^{3}$, Wolfgang Eisenreich ${ }^{2}$, Markus Fischer ${ }^{4}$ and Adelbert Bacher ${ }^{2, *}$ \\ 'Department of Biochemistry, Chungnam National University, Daejeon 305-764, Korea \\ ${ }^{2}$ Lehrstuhl für Organische Chemie und Biochemie, Technische Universität München, D-85747 Garching, Germany \\ ${ }^{3}$ Department of Medicinal Chemistry and Molecular Pharmacology, Purdue University, West Lafayette, IN 47907, USA \\ ${ }^{4}$ Lehrstuhl für Lebensmittelchemie, Universität Hamburg, D-20146 Hamburg, Germany
}

Received 11 August 2006, Accepted 24 November 2006

\begin{abstract}
Riboflavin synthase from Escherichia coli is a homotrimer of $23.4 \mathrm{kDa}$ subunits and catalyzes the formation of one molecule each of riboflavin and 5-amino-6-ribitylamino$\mathbf{2 , 4}(1 \mathrm{H}, 3 \mathrm{H})$-pyrimidinedione by the transfer of a 4-carbon moiety between two molecules of the substrate, 6,7dimethyl-8-ribityllumazine. Each subunit comprises two closely similar folding domains. Recombinant expression of the $\mathrm{N}$-terminal domain is known to provide a $\mathbf{c}_{2}$ symmetric homodimer. In this study, the binding properties of wild type as well as two mutated proteins of $\mathrm{N}$-terminal domain of riboflavin synthase with various ligands were tested. The replacement of the amino acid residue $\mathrm{A43}$, located in the second shell of riboflavin synthase active center, in the recombinant $\mathrm{N}$-terminal domain dimer reduces the affinity for 6,7-dimethyl-8-ribityllumazine. The mutation of the amino acid residue $\mathrm{C48}$ forming part of activity cavity of the enzyme causes significant ${ }^{19}$ F NMR chemical shift modulation of trifluoromethyl derivatives of 6,7-dimethyl-8-ribityllumazine in complex with the protein, while substitution of A43 results in smaller chemical shift changes.
\end{abstract}

Keywords: Escherichia coli, Lumazine, Riboflavin synthase, Site-directed mutagenesis

Present address: Hanmi Pharmaceutical Co., Ltd. Research Center, Hwaseong-si, Gyeonggi-do 445-813, Korea

*To whom correspondence should be addressed.

${ }^{1}$ Tel: 82-42-821-5482; Fax: 82-42-822-7548

E-mail: cylee@cnu.ac.kr

${ }^{2}$ Tel: 49-89-289-13360; Fax: 49-89-289-13363

E-mail: adelbert.bacher@ch.tum.de

\section{Introduction}

Riboflavin synthase of Escherichia coli catalyzes the formation of one equivalent each of riboflavin and 5-amino-6-ribitylamino2,4(1H,3H)-pyrimidinedione (Harvey and Plaut, 1966; Plaut et al., 1970; Bacher, 1991; Bacher et al., 1996) from two equivalents of 6,7-dimethyl-8-ribityllumazine (Fig. 1). Intramolecular sequence similarity shown in Fig. 2 suggested that each subunit folds into two topologically similar domains, each of which can accommodate one substrate molecule (Schott et al., 1990). This hypothesis was later confirmed by X-ray structure analysis (Liao et al., 2001; Gerhardt et al., 2002) indicating RMSD values in the range of about $1 \AA$ between the two domains of a given subunit. The dimer interface of the artificial domain dimer has been shown to mimic the interface between the N-terminal and C-terminal domains (Schott et al., 1990). Rather surprisingly, the recombinant expression of the N-terminal domain of riboflavin synthase, which is devoid of the enzymatic activities, yields a $c_{2}-$ symmetric homodimer whereas the natural full-length subunit forms a homotrimer (Eberhardt et al., 2001). The structure of the artificial N-terminal domain dimer has been determined by NMR analysis and X-ray crystallography (Truffault et al., 2001; Meining et al., 2003). The conserved amino acid residue $\mathrm{C} 48$ forms part of the active site cavity (Liao et al., 2001; Truffault et al., 2001; Meining et al., 2003) of the Nterminal domain, but its replacement by serine in riboflavin synthase of Schizosaccharomyces pombe does not significantly reduce catalytic activity (Fischer et al., 2003). On the other hand, it has been shown earlier that certain amino acids located in the second shell of the active site cavity are crucial for catalytic activity (Illarionov et al., 2001). Thus, the replacement or deletion of the conserved F2 renders the enzyme inactive, although the amino acid residue is not in direct contact with the bound substrate or product. A43, which 
is located in the close neighborhood of F2 and C48, is also highly conserved, but the impact of its replacement has not been studied as yet.

This study describes the modulation of ligand binding properties of the recombinant N-terminal domain of $E$. coli riboflavin synthase (N-RS) caused by the replacement of A43 and $\mathrm{C} 48$, respectively.

\section{Materials and Methods}

Materials. Restriction enzymes were purchased from Pharmacia and New England Biolabs. T4 DNA ligase was obtained from Gibco. Oligonucleotides were custom synthesized by MWG-Biotech. The AmpliTaq FS BigDye Terminator Cycle Sequencing Kit was from Perkin Elmer.

Chemicals. 6,7-Dimethyl-8-ribityllumazine (Bacher, 1986), 6,7bistrifluoromethyl-8-ribityllumazine hydrate (Cushman et al., 1991), and 6-(trifluoromethyl)-7-oxo-8-(D-ribityl)lumazine (Cushman et al., 1992) were prepared by published procedures.

Bacterial strains and plasmids. E. coli XL-1 blue (Stratagene) was used as a cloning and expression strain, and the plasmid pNCO 113 (Stüber et al., 1990) was used as a cloning vector (Table 1).

Bacterial cultures. Recombinant $E$. coli strains were grown in LB medium containing ampicillin $(150 \mu \mathrm{g} / \mathrm{ml})$ at $37^{\circ} \mathrm{C}$ in shaking flasks to an optical density of $0.7(490 \mathrm{~nm})$. Isopropyl- $\beta$-Dthiogalactopyranoside was added to final concentration of $0.5 \mathrm{mM}$ and incubation was continued at $37^{\circ} \mathrm{C}$ for $4 \mathrm{~h}$. The cells were harvested by centrifugation and stored at $-75^{\circ} \mathrm{C}$.
Site-directed mutagenesis. PCR-driven mutagenesis was performed with Vent DNA polymerase (New England Biolabs) as described earlier (Illarionov et al., 2001) using the plasmid pERN (Eberhardt et al., 2001) as a template. The general scheme for mutagenesis PCR involved two rounds of amplification cycles using one mismatch and two flanking primers (Table 2). During the first round, 5 amplification cycles were carried out with the respective mismatch primer and the flanking primer 2 . The second PCR round of 20 cycles was performed after the addition of the flanking primer 1 (Table 2). The amplified DNA was analyzed by agarose gel electrophoresis and purified using a QIAquick PCR Purification Kit (QIAGEN). The isolated PCR product was digested with EcoRI and PstI, purified using the QIAquick PCR Purification Kit, and ligated into pNCO113 that had been digested with the same restriction enzymes. The ligation mixtures were transformed into $E$. coli XL-1 blue cells. The nucleotide sequences of all plasmid constructs were confirmed by dideoxynucleotide sequencing using an automated 377 Prism DNA sequencer (Applied Biosystems).

Protein purification. Purification procedures were performed at $4^{\circ} \mathrm{C}$. Frozen cell mass $(5 \mathrm{~g})$ was thawed in $25 \mathrm{ml}$ of $50 \mathrm{mM}$ Tris hydrochloride, $\mathrm{pH} 7.2$, containing $0.5 \mathrm{mM}$ EDTA and $0.5 \mathrm{mM}$ dithiothreitol (buffer A). The suspension was subjected to ultrasonic treatment and then centrifuged. The supernatant was dialyzed against 10 volumes of buffer $\mathrm{A}$ and centrifuged. The supernatant was passed through a column of Q-Sepharose Fast Flow $(2 \times 18$ $\mathrm{cm}$; Amersham Pharmacia) pre-equilibrated with buffer A (flow rate, $1 \mathrm{ml} / \mathrm{min}$ ). The column was washed with $100 \mathrm{ml}$ of buffer $\mathrm{A}$ and developed with a linear gradient of 0 to $0.5 \mathrm{M} \mathrm{NaCl}$ in buffer $\mathrm{A}$ (total volume, $280 \mathrm{ml}$ ). The $\mathrm{N}$-terminal domain of riboflavin synthase (N-RS) was eluted from 200 to $240 \mathrm{ml}$. Fractions were combined and concentrated by ultrafiltration. The solution was

Table 1. Bacterial strains and plasmids used in this study

\begin{tabular}{|c|c|c|}
\hline Strains/Plasmids & Relevant Characteristics & Source \\
\hline \multicolumn{3}{|l|}{ Strains } \\
\hline E.coli $\mathrm{M} 15$ & Expression strain & Zamenhof and Villarejo, 1972 \\
\hline E. coli XL-1 Blue & Cloning strain & Stratagene \\
\hline \multicolumn{3}{|l|}{ Plasmids } \\
\hline pNCO 113 & Expression vector & Stüber et al., 1990 \\
\hline $\mathrm{pERN}$ & $\begin{array}{l}\text { pNCO113 containing the gene for the wild type N-terminal domain } \\
\text { of } E \text {. coli riboflavin synthase }\end{array}$ & this study \\
\hline pERN-A43L & $\begin{array}{l}\text { pNCO113 containing the gene for the A43L mutant of N-terminal } \\
\text { domain }\end{array}$ & this study \\
\hline pERN-C48S & $\begin{array}{l}\text { pNCO113 containing the gene for the C48S mutant of N-terminal } \\
\text { domain }\end{array}$ & this study \\
\hline
\end{tabular}

Table 2. Oligonucleotides used for the construction of the N-terminal domain of riboflavin synthase and for the site directed mutagenesis of N-RS. Mutated bases are underlined

\begin{tabular}{ccl}
\hline Primer & Amino acid replacement & \multicolumn{1}{c}{ Nucleotide sequence } \\
\hline 1 & none & 5' ACACAGAATTCATTAAAGAGGAGAAATTAACC ATG \\
2 & none & 5'-GTCCTGCAG TTA GTG TCC GCC \\
3 & A43 $\rightarrow \mathrm{L}$ & 5'-GCT TCC GTG $\underline{\text { CTG CAT AAC GGT TG }}$ \\
4 & $\mathrm{C} 48 \rightarrow \mathrm{S}$ & 5'-CAT AAC GGT TGC $\underline{\text { AGC CTG ACC GTG AC }}$ \\
\hline
\end{tabular}


<smiles>[R]N1C2=NC(=O)NC(=O)C2=NC(C)=C(C)N1[R]</smiles><smiles>[R]n1c2nc(=O)[nH]c(=O)c-2nc2cc(C)c(C)cc21</smiles><smiles>[R]Nc1[nH]c(=O)[nH]c(=O)c1N</smiles>

Fig. 1. Riboflavin synthase reaction. 1, 6,7-dimethyl-8-ribityllumazine; 2, riboflavin; 3, 5-amino-6-ribitylamino-2,4(1H,3H) pyrimidinedione.

placed on a column of Superdex $75 \mathrm{HP} 26 / 60(2 \times 60 \mathrm{~cm}$; Amersham Pharmacia), which was developed with $360 \mathrm{ml}$ of $100 \mathrm{mM}$ phosphate, $\mathrm{pH}$ 7.0. The protein was eluted from 185 to $215 \mathrm{ml}$. Fractions were combined and concentrated. The concentration of purified protein was determined photometrically using an absorbance coefficient of $5,600 \mathrm{M}^{-1} \mathrm{~cm}^{-1}$ and ligand-free proteins were prepared as described earlier (Eberhardt et al., 2001).

Fluorescence titration. Fluorescence measurements were performed using a Hitachi fluorescence spectrophotometer FS-2000 (Hitachi). Solutions of 6,7-dimethyl-8-ribityllumazine or riboflavin in buffer A were added in $5 \mathrm{ml}$ aliquots to $3 \mathrm{ml}$ of a solution containing $1 \mathrm{mg}$ of protein per ml. Fluorescence was monitored after each addition (6,7-dimethyl-8-ribityllumazine: excitation, $410 \mathrm{~nm}$; emission, 490 $\mathrm{nm}$; riboflavin: excitation, $445 \mathrm{~nm}$; emission, $520 \mathrm{~nm}$ ). Dissociation constants were determined using the program Origin 6.0 (Microcal Software).

NMR ligand perturbation studies. ${ }^{19} \mathrm{~F}$ NMR spectra were recorded at $338 \mathrm{MHz}$ using an AM360 NMR spectrometer from Bruker Instruments. Measurements were performed at $24^{\circ} \mathrm{C}$. The samples contained $70 \mathrm{mM}$ phosphate, $\mathrm{pH} 7.0,100 \mathrm{mM} \mathrm{NaCl}, 10 \%$ $\mathrm{D}_{2} \mathrm{O}$ and 10 to $30 \mathrm{mg}$ of protein per $\mathrm{ml}$. Ligands were added as indicated. Experimental parameters were as follows: pulse angle, $30^{\circ}(2 \mu \mathrm{S})$; repetition rate, $0.5 \mathrm{~s} ; 32 \mathrm{k}$ data set; line broadening as indicated. Chemical shift values were normalized to an external standard containing sodium trifluoroacetate, $\mathrm{pH}$ 7.0.

Molecular modeling of the N-terminal domain of riboflavin synthase bound to trifluoromethyllumazine derivatives. The file 1PKV.pdb was imported into Sybyl 7.2. The atom types and bond orders of several atoms in the two riboflavin molecules in the crystal structure file were corrected. Hydrogens were added and the protein termini were fixed to be charged. The energy of the proteinriboflavin complex was minimized with all of the heavy atoms frozen in an aggregate in order to minimize the energies of the hydrogen atoms. After minimization, one of the riboflavin molecules was modified to create structures 5 and 7 (Fig. 5). One of the two riboflavin molecules in the original structure was then

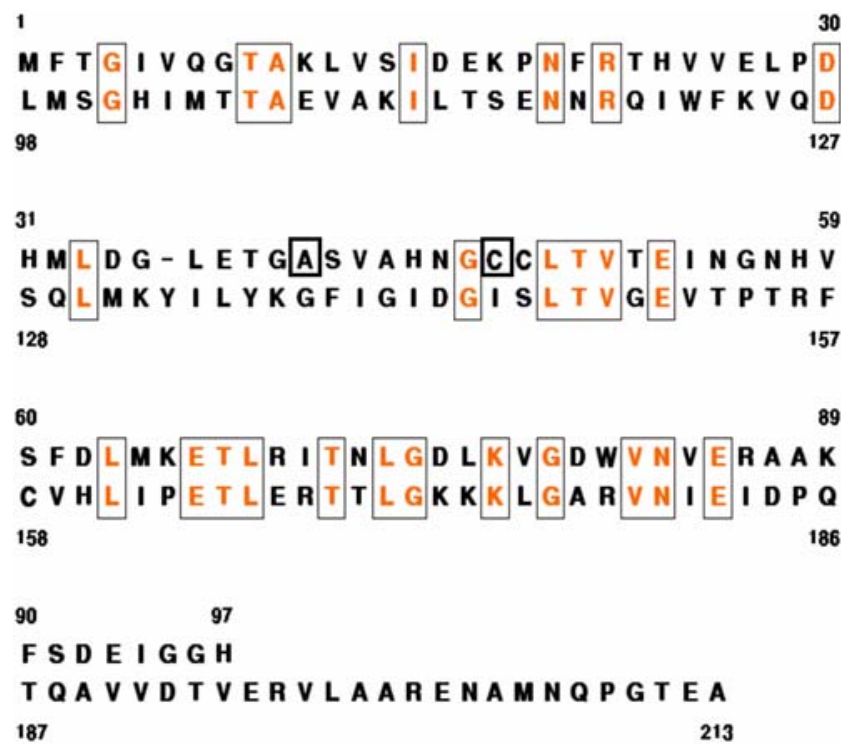

Fig. 2. Internal amino acid similarity between N-terminal half and C-terminal half of riboflavin synthase from E. coli. Identical amino acids are shown in gray letters. The residues A43 and C48 subjected to mutagenesis are boxed.

replaced by either 5 or $\mathbf{7}$ by overlapping either one of them with riboflavin then deleting the structure of riboflavin. The energies of the resulting complexes were minimized to converge at a $0.05 \mathrm{kcal} /$ (mol $\cdot \AA$ ) gradient between iterations using the MMFF94s force field, MMFF94 charge, and a distance-dependent dielectric function. During energy minimization, all the atoms of the protein and the remaining riboflavin molecule were frozen while allowing only the ligand molecule 5 or 7 to move.

\section{Results}

In earlier ${ }^{19} \mathrm{~F}$ NMR studies on riboflavin synthase, the ${ }^{19} \mathrm{~F}$ NMR signal complexity of trifluoromethyllumazine derivatives bound to riboflavin synthase suggested that the ligands could bind to the protein in several different states (Scheuring et al., 1996). On the other hand, binding of trifluoromethyllumazine derivatives to the dimeric N-RS showed only a single signal for each respective trifluoromethyl group (Eberhardt et al., 2001). This suggested that the subunits of the homotrimeric enzyme are not topologically equivalent, whereas those of the artificial dimer are equivalent. That hypothesis was subsequently confirmed by X-ray structure analysis indicating that only one $\mathrm{N}$-terminal domain in conjunction with a C-terminal domain of an adjacent subunit can form an active site at any time (Liao et al., 2001; Gerhardt et al., 2002). In order to simplify the NMR signal pattern, we decided to perform the present study with the inherently symmetrical N-terminal domain rather than the inherently asymmetric, trimeric enzyme.

The codons specifiying the conserved amino acids C48 and A43 of the proteins were replaced by PCR-mediated mutagenesis. The cognate $\mathrm{C} 48 \mathrm{~S}$ and $\mathrm{A} 43 \mathrm{~L}$ mutant proteins 


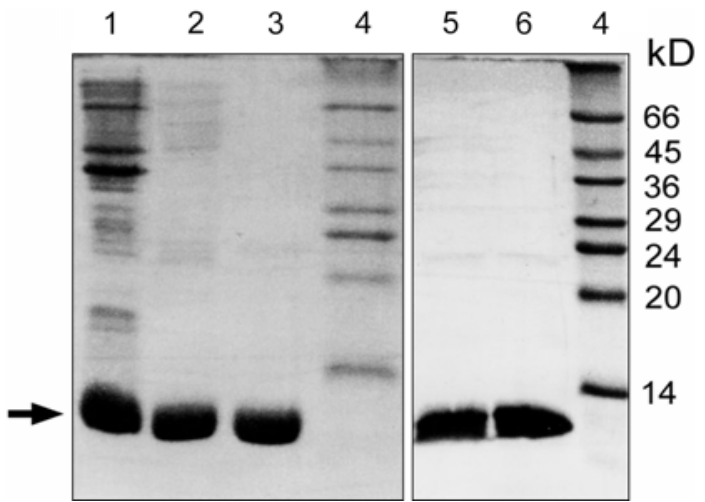

Fig. 3. SDS-polyacrylamide gel electrophoresis. 1, crude extract of E. coli M15 [pREP4] containing pERN plasmid; 2, N-RS derived from M15 [pREP4, pERN] strain after purification on QSepharose Fast Flow; 3, N-RS after purification on Superdex 75; 4, protein marker; 5, purified A43L; 6, purified C48S. An arrow indicates target proteins.

could be expressed in high yield (10 to $20 \%$ of total cell protein) in recombinant $E$. coli strains. The apparent mass as determined by SDS/PAGE was about $10 \mathrm{kDa}$, which was in agreement with the mass value predicted from the known amino acid sequence of the recombinant protein (Fig. 3). The mutant proteins showed the same retention volume in gel filtration experiments as the wild type N-terminal domain. This result indicates that the mutations did not affect the homodimer association.

Binding of 6,7-dimethyl-8-ribityllumazine or riboflavin by the proteins under study was monitored by fluorescence titration. Binding of 6,7-dimethyl-8-ribityllumazine is accompanied by almost complete quenching of the lumazine fluorescence. The relative quantum yield of the bound ligand as compared to the free ligand is less than $3 \%$. Scatchard plots obtained from the fluorescence titration data revealed approximately two bound lumazine or riboflavin ligand molecules per dimeric protein (Fig. 4). Dissociation constants are shown in Table 3. The affinity for 6,7-dimethyl-8-ribityllumazine was not significantly changed by the $\mathrm{C} 48 \mathrm{~S}$ mutation. On the other hand, the affinity of the A43L mutant for this ligand is reduced about 5-fold. A similar experiment with riboflavin as a ligand resulted in dissociation constants of 7,9 and $40 \mu \mathrm{M}$ for the wild-type protein and the $\mathrm{C} 48 \mathrm{~S}$ and $\mathrm{A} 43 \mathrm{~L}$ mutants, respectively (Table 3, Fig. 4B). Again, the A43L mutant showed the lowest ligand affinity among the proteins tested. Possible reasons for this finding will be discussed in detail below.

The fluorine-substituted ligands shown in the Fig. 5 have been used extensively in earlier ${ }^{19} \mathrm{~F}$ NMR perturbation experiments with homotrimeric riboflavin synthases and with the recombinant N-terminal domain of the E. coli enzyme (Cushman et al., 1991, 1992, Scheuring et al., 1996; Eberhardt et al., 2001). Similar ${ }^{19}$ F NMR ligand perturbation experiments (Scheuring et al., 1994ab) were also carried out with the monomeric lumazine proteins from Photobacterium
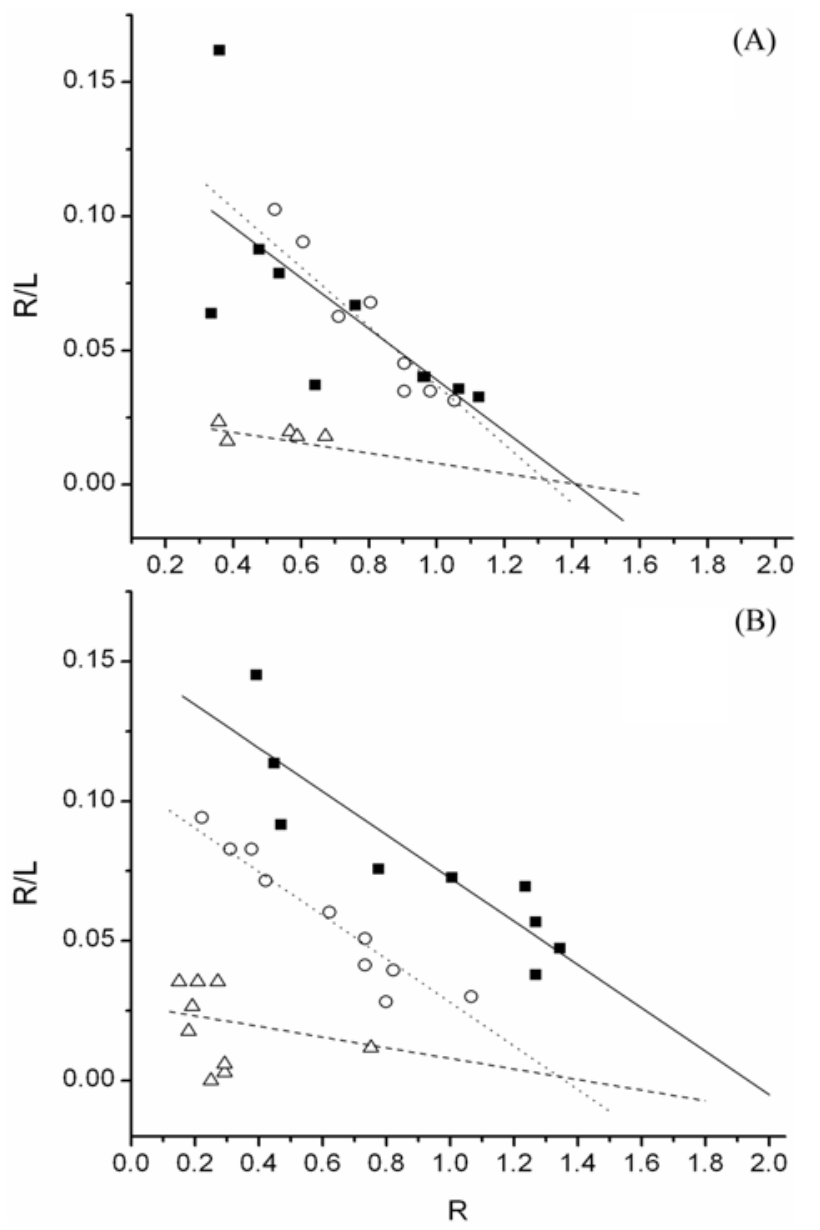

Fig. 4. Scatchard plots based on fluorescence titration experiments. Ligand: A, 6,7-dimethyl-8-ribityllumazine; B, riboflavin. Protein: wild type N-RS $(\boldsymbol{\square})$; A43L $(\triangle)$; C48S $(\bigcirc)$. Lines indicate linear fit of experimental data. $\mathrm{R}$, number of ligand molecules per protein molecule; L, concentration of free ligand (concentration of protein has been calculated per protein dimer).

Table 3. Ligand binding affinities

\begin{tabular}{ccc}
\hline Protein & \multicolumn{2}{c}{$\mathrm{K}_{\mathrm{D}}$} \\
\hline & 6,7-dimethyl-8-ribitylumazine & riboflavin \\
N-RS & $8 \mu \mathrm{M}$ & $7 \mu \mathrm{M}$ \\
A43L & $40 \mu \mathrm{M}$ & $40 \mu \mathrm{M}$ \\
C48S & $8 \mu \mathrm{M}$ & $9 \mu \mathrm{M}$ \\
\hline
\end{tabular}

phosphoreum and Photobacterium leiognathi which serve as optical transponders in biolumionescence emission by certain marine bacteria but are apparently devoid of enzyme activity (O'Kane and Lee 1985; O'Kane et al., 1991). These proteins were all shown to bind 6-trifluoromethyl-7-oxo-8-ribityllumazine (Compound 7) as well as epimer A (Compound 5) of the covalent hydrate of 6,7-bis(trifluoromethyl)-8-ribityllumazine, but not its diastereomer, Compound 6 . The same experimental approach has now been applied to the study of the A43L and $\mathrm{C} 48 \mathrm{~S}$ mutants. At the neutral $\mathrm{pH}$, compound 7 is present as an 


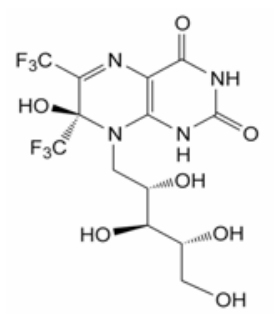

5

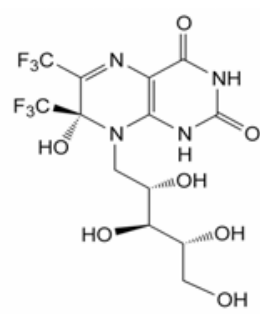

6

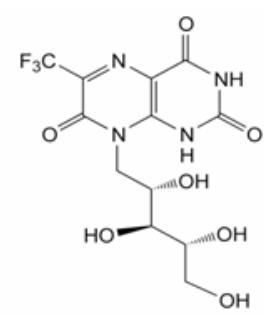

7<smiles>CC(C)(c1nc2c(=O)[nH]c(=O)nc-2n(C[C@H](O)[C@H](O)[C@H](O)CO)c1[O-])C(F)(F)F</smiles>

1<smiles></smiles>

Fig. 5. Chemical structures of diastereomeric 6,7-bis (trifluoromethyl)-8-ribityllumazine hydrate: epimer A (5) and epimer B (6), as well as of 6-trifluoromethyl-7-oxo-8ribityllumazine (7). The structures of anionic form of the compound $\mathbf{7}$ and the compound $\mathbf{1}$ in Fig. 1 are shown at bottom.

anionic form shown at the bottom in Fig. 5 and is structurally similar to the exomethylene form of the 6,7-dimethyl-8ribityllumazine anion (1 in Fig. 5) that has been proposed to serve as an intermediate in the riboflavin synthase reaction (Cushman et al., 1991, 1992). In line with the results published earlier (Eberhardt et al., 2001), titration experiments with Compound 7 and the N-RS showed signals at $7.67 \mathrm{ppm}$ for the free ligand and $11.63 \mathrm{ppm}$ for the protein-bound ligand (Table 4, Fig. 6). The signal of the free ligand is broadened to a linewidth of about $27 \mathrm{~Hz}$, and the signal of the bound ligand is broadened to about $49 \mathrm{~Hz}$.

The replacement of $\mathrm{C} 48$ by serine had a major impact on the ${ }^{19} \mathrm{~F}$ NMR chemical shift values of the bound ligand. The titration of this mutant protein with Compound 7 showed signals at $7.67 \mathrm{ppm}$ for the free ligand and $10.25 \mathrm{ppm}$ for the protein-bound ligand. In comparison to the wild type N-RS, the ${ }^{19} \mathrm{~F}$ NMR signal of the protein-bound $6-\mathrm{CF}_{3}$ group is shifted upfield by $1.38 \mathrm{ppm}$ in case of the C48S mutant. The signal of the free ligand is broadened to a linewidth of about $24 \mathrm{~Hz}$, and the signal of the bound ligand is broadened to about $42 \mathrm{~Hz}$. A similar set of experiments was carried out

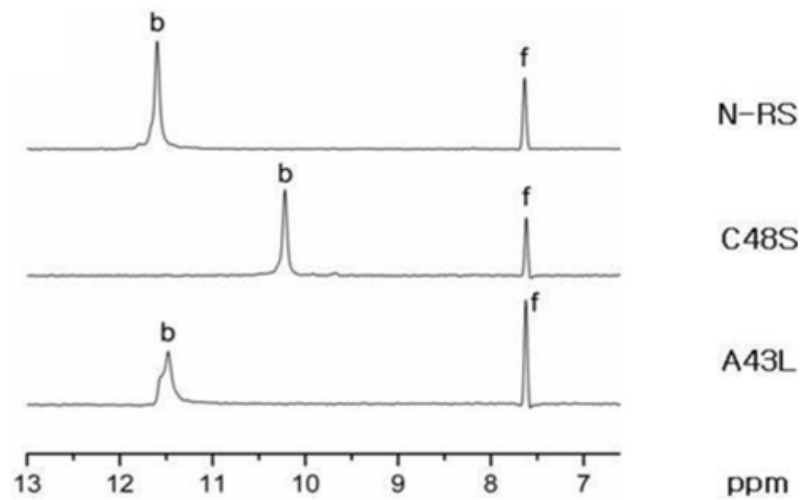

Fig. 6. Protein perturbation experiments monitored by ${ }^{19} \mathrm{~F}$ NMR. Ligand, Compound 7, Proteins: N-RS, wild type; A43L and C48S are the respective mutant variants of N-RS; f, signals from free ligand; $b$, signals from bound ligand.

Table 4. NMR data of Compound 7 in complex with N-RS or mutant variants

\begin{tabular}{cc}
\hline Protein & ${ }^{19} \mathrm{~F}$ chemical shift, ppm \\
\hline N-RS & 11.63 \\
A43L & 11.52 \\
C48S & 10.25 \\
Free ligand & 7.67 \\
\hline
\end{tabular}

with the A43L mutant protein. The bound monotrifluoromethyl-substituted lumazine analog showed a signal at 11.52 ppm, which is only $0.11 \mathrm{ppm}$ upfield shifted by comparison with the wild type N-RS (Table 4, Fig. 6). On the other hand, the signal of the bound ligand is broadened in this case to a linewidth of about $76 \mathrm{~Hz}$, and is approximately two times broader than the signal of ligand in complex with N-RS wild type or C48S mutant.

Two diastereomeric covalent hydrates of 6,7-bis (trifluoromethyl)-8-ribityllumazine (Compound 5 and 6) (Fig. 5) differ by their configuration at C-7. Binding of Compound 5 to the N-RS led to the ${ }^{19} \mathrm{~F}$ NMR spectrum shown in Fig. 7. The position 6 trifluoromethyl group of the enzyme-bound ligand appears as a broadened signal with a linewidth of 50 $\mathrm{Hz}$ at a chemical shift of $15.6 \mathrm{ppm}, 3.4 \mathrm{ppm}$ downfield by comparison with the signal for the free ligand at $12.2 \mathrm{ppm}$ (Table 5). The signal for the enzyme-bound position 7 trifluoromethyl group with a linewidth of $54 \mathrm{~Hz}$ is observed at $-6.5 \mathrm{ppm}, 1.6 \mathrm{ppm}$ downfield shifted by comparison with the signal of the free ligand at $-8.1 \mathrm{ppm}$. The signals for the free ligand have a linewidth of $34 \mathrm{~Hz}$. The signal of the position 6 trifluoromethyl group of the ligand bound to the C48S mutant is located at $15.0 \mathrm{ppm}, 0.6 \mathrm{ppm}$ upfield by comparison with the corresponding signal at $15.6 \mathrm{ppm}$ in the spectrum of the ligand wild type N-RS. On the other hand, the signal of the position 7 trifluormethyl group is observed at $-7.7 \mathrm{ppm}, 1.2$ ppm upfield by comparison with the respective signal at -6.5 $\mathrm{ppm}$ in the spectrum of the ligand with wild type N-RS. ${ }^{19} \mathrm{~F}$ 


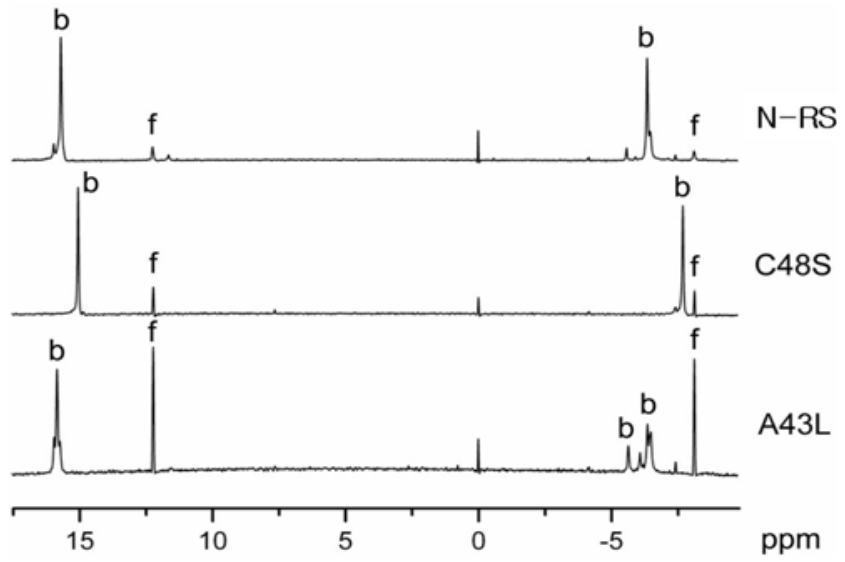

Fig. 7. Protein perturbation experiments monitored by ${ }^{19} \mathrm{~F}$ NMR. Ligand, Compound 5, Proteins: N-RS, wild type; A43L and C48S are the respective mutant variants of N-RS; f, signals from free ligand; $b$, signals from bound ligand.

Table 5. NMR data of Compound 5 in complex with N-RS or mutant variants

\begin{tabular}{ccc}
\hline Protein & \multicolumn{2}{c}{${ }^{19} \mathrm{~F}$ chemical shift, $\mathrm{ppm}$} \\
\hline & $6-\mathrm{CF}_{3}$ & $7-\mathrm{CF}_{3}$ \\
$\mathrm{~N}-\mathrm{RS}$ & 15.6 & -6.5 \\
$\mathrm{~A} 43 \mathrm{~L}$ & 15.8 & $-6.1,-6.4$ \\
$\mathrm{C} 48 \mathrm{~S}$ & 15.0 & -7.7 \\
Free ligand & 12.2 & -8.1 \\
\hline
\end{tabular}

NMR spectra recorded with the A43L mutant showed three signals at $15.8 \mathrm{ppm}\left(6-\mathrm{CF}_{3}\right)$ and four to five signals at a shift range of -6.1 to $-6.4 \mathrm{ppm}\left(7-\mathrm{CF}_{3}\right)$ (Table 5). The signals due to bound ligand are broadened to $83 \mathrm{~Hz}$ and $86 \mathrm{~Hz}$, respectively.

\section{Discussion}

X-ray structure analysis of $E$. coli and $S$. pombe riboflavin synthases revealed the absence of trigonal molecular symmetry for the homotrimer (Liao et al., 2001). Moreover, protein perturbation studies monitored by ${ }^{19} \mathrm{~F}$ NMR with fluorine-substituted intermediate analogues (Cushman et al., 1991, 1992) indicated that the binding sites of the homotrimeric riboflavin synthases are not topologically equivalent; the replacement of certain amino acids at the N-terminal or Cterminal domain affected virtually all signals attributed to bound ligands (Illarionov et al., 2001). On the other hand, monitoring the ligand bound to the recombinant aminodomain of riboflavin synthase by ${ }^{19} \mathrm{~F}$ NMR spectroscopy was shown to produce simpler results with regard to ligand perturbation data due to the absence of the second binding site at the carboxy-terminal domain (Eberhardt et al., 2001). For this reason, the effect of single amino acid replacements in the amino-terminal substrate binding site of riboflavin synthase was tested using the artificial amino-terminal domain in the present study.

Both mutations analyzed in this study modified proteinligand interaction, although both in their own different ways. The amino acid residue C48 is located in the first shell of the active site of riboflavin synthase. The exchange of sulfur with oxygen in the side chain of this amino acid created substantial perturbation of ${ }^{19} \mathrm{~F}$ NMR signals obtained from Compound 7 and Compound 5 bound to the protein. The ${ }^{19} \mathrm{~F}$ NMR signals were shifted by up to $1.4 \mathrm{ppm}$ by comparison with the wild type protein. It seems plausible that this replacement has changed essentially the electron density in the vicinity of C-6 and C-7 of bound ligand. On the other hand, C48S replacement had little impact on the affinity of the artificial N-terminal domain for riboflavin or the pyrimidinedione derivative 3 (Fig. 1).

The replacement of A43, which is located in the second shell of the riboflavin synthase active center, had a more profound impact on the affinity of the protein for both riboflavin and 6,7-dimethyl-8-ribityllumazine. For example, the $K_{D}$ for riboflavin was shown to be $40 \mu \mathrm{M}$ for the $\mathrm{A} 43 \mathrm{~L}$ mutant by comparison with $7 \mu \mathrm{M}$ or $9 \mu \mathrm{M}$ for the N-RS or C48S mutant, respectively. With regard to the ligand perturbation data, the $\mathrm{A} 43 \mathrm{~L}$ replacement resulted in less substantial modification of the NMR signal pattern as compared to the C48S mutant. The signals for the trifluoromethyl groups were maximally shifted by approximately 0.2-0.4 ppm as compared to the wild type protein. On the other hand, the apparent multiplicity of ${ }^{19} \mathrm{~F}$ NMR signals has been increased for both fluorinated ligands as shown in the Figs. 6 and 7 . This signal multiplicity most likely reflects multiple binding modes in the A43L protein.

The energy-minimized structures of 5 and $\mathbf{7}$ bound to $E$. coli riboflavin synthase (Fig. 8) are very similar to each other and to the crystal structure of the enzyme complex with bound riboflavin (Meining et al., 2003). Only minor deviations in the positions of corresponding atoms were noted. The smaller ${ }^{19} \mathrm{~F}$ NMR chemical shift perturbations observed for the A43L mutant vs. the C48S mutant for both of the fluorinated ligands are consistent with the closer proximity of the $\mathrm{C} 48$ residue to the trifluoromethyl groups of both compounds. The distance from the nearest fluorine atom of the $6-\mathrm{CF}_{3}$ group of 5 to the sulfur of $\mathrm{C} 48$ is calculated to be $4.1 \AA$, while that of the $7-\mathrm{CF}_{3}$ group is $3.0 \AA$. The corresponding distances to the $\beta$-carbon of the A43 residue are $9.3 \AA$ and $7.8 \AA$, respectively. The $\mathrm{C} 48 \mathrm{~S}$ mutation results in upfield ${ }^{19} \mathrm{~F}$ NMR shifts of the signals for all of the trifluoromethyl groups in both ligands. Similar upfield ${ }^{19} \mathrm{~F}$ NMR shifts have previously been noted to result from $\mathrm{O}-\mathrm{H} \cdots \cdot \mathrm{F}$ hydrogen bonding, and it is conceivable that the upfield shifts observed in the present case may be due to the formation hydrogen bonds from the S48 hydroxyl to the fluorine atoms of the ligands (Takemura et al., 2004). Although hydrogen bonds of the type $\mathrm{S}-\mathrm{H} \cdots \mathrm{F}$ are also possible, they are expected to be weaker than the typical hydrogen bonds involving O-H donors (Allen et al., 1997).

The ${ }^{19} \mathrm{~F}$ NMR chemical shifts observed in the bound forms 

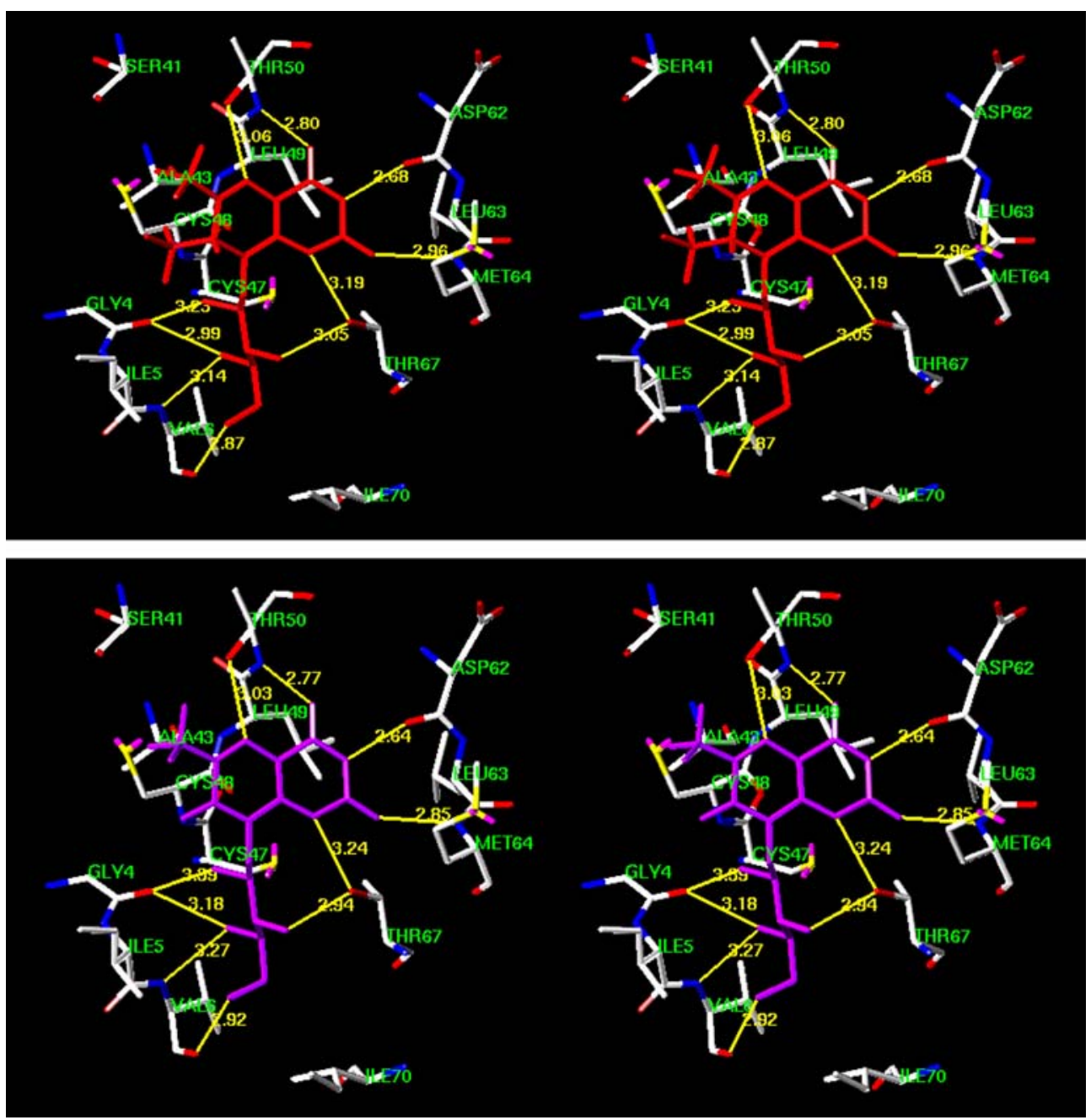

Fig. 8. Hypothetical models of the binding of (7R)-6,7-bis(trifluoromethyl)-7-hydroxy-8-ribityllumazine (5) (top) and 6-trifluoromethyl7-oxo-8-ribityllumazine (7) (bottom) to the $\mathrm{N}$-terminal domain of E. coli riboflavin synthase. The stereodiagrams are programmed for wall-eyed (relaxed) viewing.

of both ligands are at lower field relative to the free ligand, and this effect is apparent in the N-RS protein as well as in the two C48S and A43L mutants. Hydrogen bonding of Thr50 side chain hydroxyl group to $\mathrm{N} 5$ and the Thr50 backbone $\mathrm{NH}$ to the lumazine carbonyl oxygen at $\mathrm{C} 4$ would be expected to decrease electron density at the $\mathrm{CF}_{3}$ groups and therefore deshield them. This effect could also be reinforced by hydrogen bonding of the Thr67 side chain hydroxyl group to N1.

The results suggest that the replacement of $\mathrm{C} 48$ has changed the electron density topology in the $\mathrm{N}$-terminal substrate binding site in the vicinity of C-6 and C-7 atoms of bound ligand. This replacement, however, eventually did not change the affinity of the N-terminal binding site for riboflavin or pyrimidinedione derivative 3 (Fig. 1). On the contrary, the replacement of the A43 residue was accompanied by less substantial perturbation of ${ }^{19} \mathrm{~F}$ NMR spectra as compared to the C48S mutant, although the apparent complexity of ${ }^{19} \mathrm{~F}$
NMR signals has been increased. On the other hand, this relatively conserved A43L replacement substantially decreased the affinity of protein to the ligands tested. Taken together, these findings suggest that the A43L replacement caused substantial perturbation of the overall binding site topology.

Acknowledgments This work was supported by grants from the cooperative program between the Korea Science and Engineering Foundation (20025-209-07-2) and the Deutsche Forschungsgemeinsschaft (FI 824), as well as from the NIH Grant GM51469.

\section{References}

Allen, F. H., Bird, C. M., Rowland, R. S. and Raithby, P. R. (1997) Hydrogen-bond acceptor and donor properties of divalent sulfur (Y-S-Z and R-S-H). Acta Cryst. 53, 696-701. 
Bacher, A. (1986) Heavy riboflavin synthase from Bacillus subtilis. Methods Enzymol. 122, 192-199.

Bacher, A. (1991) Biosynthesis of flavins; in Chemistry and Biochemistry of Flavoproteins, Müller, F. (ed.) pp. 215-259, Chemical Rubber and Co., Boca Raton, USA.

Bacher, A., Eberhardt, S. and Richter, G. (1996) Biosynthesis of riboflavin; in Escherichia coli and Salmonella, Neidhard, F. C. (ed.), pp. 657-664, American Society for Microbiology, Washington, USA.

Cushman, M., Patel, H. H., Bacher, A. and Scheuring, J. (1991) Synthesis of epimeric 6,7-bis(trifluoromethyl-8-ribityl)lumazine hydrates. Stereoselective interaction with the light riboflavin synthase of Bacillus subtilis. J. Org. Chem. 56, 4603-4608.

Cushman, M., Patel, H. H., Scheuring, J. and Bacher, A. (1992) ${ }^{19} \mathrm{~F}$ NMR studies on the mechanism of riboflavin synthase. Synthesis of 6-(trifluoromethyl)-7-oxo-8-(D-ribityl)lumazine and 6-(trifluoromethyl)-7-methyl-8-(D-ribityl)lumazine. J. Org. Chem. 57, 5630-5643.

Eberhardt, S., Zingler, N., Kemter, K., Richter, G., Gimbel, W., Cushman, M. and Bacher, A. (2001) Domain structure of riboflavin synthase. Eur. J. Biochem. 268, 4315-4323.

Fischer, M., Schott, A. K., Kemter, K., Feicht, R., Richter, G., Illarionov, B., Eisenreich, W., Gerhardt, S., Cushman, M., Steinbacher, S., Huber, R. and Bacher, A. (2003) Riboflavin synthase of Schizosaccharomyces pombe. Protein dynamics revealed by ${ }^{19} \mathrm{~F}$ NMR protein perturbation experiments. $B M C$ Biochem. 4, 1-18.

Gerhardt, S., Schott, A., Kairies, N., Cushman, M., Illarionov, B., Eisenreich, W., Bacher, A., Huber, R., Steinbacher, S. and Fischer, M. (2002) Studies on the reaction mechanism of riboflavin synthase X-ray crystal structure of a complex with 6carboxyethyl-7-oxo-8-ribityllumazine. Structure 10, 1371-1381

Harvey, R. A. and Plaut, G. W. E. (1966) Riboflavin synthetase from yeast. Properties of complexes of the enzyme with lumazine derivatives and riboflavin. J. Biol. Chem. 242, 21202130.

Illarionov, B., Kempter, K., Eberhardt, S., Richter, G., Cushman, M. and Bacher, A. (2001) Riboflavin synthase of Escherichia coli. Effect of single amino acid substitution on reaction rate and ligand binding properties. J. Biol. Chem. 276, 1152411530 .

Liao, D. I., Wawrzak, Z., Calabrese, J. C., Vitanen, P. V. and Jordan, D. B. (2001) Crystal structure of riboflavin synthase. Structure 9, 399-408.

Meining, W., Eberhardt, S., Bacher, A. and Ladenstein, R. (2003) The structure of the N-terminal domain of riboflavin synthase in complex with riboflavin at $2.6 \AA$ resolution. J. Mol. Biol. 331, 1053-1063.

O'Kane, D. J. and Lee, J. (1985) Physical characterization of lumazine proteins from Photobacterium. Biochemistry 12, 1467-1475.

O'Kane, D. J., Woodward, B., Lee, J. and Prasher, D. C. (1991) Borrowed proteins in bacterial bioluminescence. Proc. Natl. Acad. Sci. USA 88, 1100-1104.

Plaut, G. W. E., Beach, R. L. and Aogaichi, T. (1970) Studies on the mechanism of elimination of protons from the methyl groups of 6,7-dimethyl-8-ribyllumazine by riboflavin synthetase. Biochemistry 9, 771-785

Scheuring, J., Lee, J., Cushman, M., Patel, H., Patrick, D. A. and Bacher, A. (1994a) (Trifluoromethyl)lumazine derivative as ${ }^{19} \mathrm{~F}$ NMR probes for lumazine protein. Biochemistry 33, 76347640.

Scheuring, J., Lee, J., Cushman, M., Oschkinat, H. and Bacher, A. (1994b) ${ }^{19} \mathrm{~F}$ NMR studies on lumazine protein from Photobacterium phosphoreum; in Flavins and Flavoprotein, Yagi, K. (ed.) pp. 75-78, Walter de Gruyter, Berlin, Germany.

Scheuring, J., Fischer, M., Cushman, M., Lee, J., Bacher, A. and Oschkinat, H. (1996) NMR analysis of site-specific ligand binding in oligomeric protein. Dynamic studies on the interaction of riboflavin synthase with trifluoromethylsubstituted intermediates. Biochemistry 35, 9637-9646.

Schott, K., Kellerman, J., Lottspeich, F. and Bacher, A. (1990) Riboflavin synthase of Bacillus subtilis. Purification and amino acid sequence of the alpha subunit. J. Biol. Chem. 265, 42044209.

Stüber, D., Matile, H. and Garotta, G. (1990) System for high level production in Escherichia coli and rapid purification of recombinant proteins. Application to epitope mapping, preparation of antibodies, and structure function analysis; in Immunological Methods IV, Lefkovits, I. and Pernis, P. (eds.), pp. 121-152, Academic Press, Orlando, USA.

Takemura, H., Kotoku, M., Yasutake, M. and Shinmyozu, T. (2004) 9-Fluoro-18-hydroxy [3,3]metacyclophane: synthesis and estimation of a C-F.-H-O hydrogen bond. Eur. J. Org. Chem. 69, 2019-2024.

Truffault, V., Coles, M., Diercks, T., Abelmann, K., Eberhardt, S., Lüttgen, H., Bacher, H., and Kessler, H. (2001) The solution structure of the N-terminal domain of riboflavin synthase. $J$. Mol. Biol. 309, 949-960.

Zamenhof, P. J. and Villarejo, M. (1972) Construction and properties of Escherichia coli strains exhibiting complementation of galactosidase fragments in vivo. J. Bacteriol. 110, 171-178. 